\title{
Response of three Bambara groundnut landraces to pre-sowing hydration in Botswana
}

\author{
Gabatshele M. Legwaila*1, Simon K. Karikari ${ }^{1}$, Kgomotso Mogamisi ${ }^{1}$ and Thembinkosi \\ Mathowa ${ }^{1}$ \\ ${ }^{1}$ Department of Crop Science and Production, Botswana College of Agriculture, Private Bag \\ 0027, Gaborone, Botswana
}

\begin{abstract}
To investigate the response of Bambara groundnut landraces to pre-sowing hydration, three experiments were conducted on three bambara groundnut landraces; OM1, Diphiri cream (DC) and Gaborone cream (GC) in the greenhouse at Botswana College of Agriculture, Botswana, in 2011. The experimental designs were completely randomized design (CRD) with 5 pre-sowing hydration; (6, 12, 24, 48, $72 \mathrm{hrs})$ and the control, each replicated four times. Increasing hydration time from 12 to 72 hrs significantly $(p \leq 0.01)$ increased the final germination for GC up to $87 \%$ and significantly increased OM1 germination up to $57 \%$ at $24 \mathrm{hrs}$. However, there was a significant decrease in final germination for DC. There were significant $(p \leq 0.01)$ differences within and across the landraces for seedling emergence; GC had the highest emergence of up to $100 \%$ at $24 \mathrm{hrs}$. Across the three landraces GC and DC significantly ( $p \leq 0.05)$ increased stem dry diameter at 6,12 and $24 \mathrm{hrs}$ pre-sowing hydration. Moreover, pre-sowing hydration treatments had significant $(p \leq 0.01)$ effect within the three Bambara landraces root dry matters and no significant ( $p>0.05$ ) effect on GC and DC leaf dry matter. Hydrating seeds for 24 hrs improved germination, seedling emergence, leaf and stem dry matter accumulation of bambara groundnut landraces.

Keywords: Bambara landraces, pre-sowing hydration, germination, seedling emergence and dry matter
\end{abstract}

\section{INTRODUCTION}

In Botswana, bambara groundnut (Vigna subterranea L. Verdic) is grown mainly for seeds by small-holder farmers. They are eaten fresh when semi-ripe and pulse when dry and mature. Though the crop is drought tolerant, its performance is low mainly due to poor germination and seedling establishment. Bambara groundnut is often grown as a secondary crop and is planted late after food crops such as maize and other crops have been sown (Linnemann, 1990). The period during which the crop is produced is often associated with low moisture content. This may be a major contributory factor to the variability in seedling establishment.

Pre-sowing hydration is a common treatment that improves germination and seedling emergence of many crops. Seed priming is a process of hydrating and dehydrating seeds following various protocols which results in improvement in seeds vigor, increased rate of germination and more uniform emergence under wide range of field environments (Modi, 2005). Berchie et al. (2011) observed that the final seedling establishment was enhanced by soaking bambara groundnut seed for $24 \mathrm{hrs}$. The results of this study where seeds were soaked in tap water, provides farmers with a cheap and simple technology which can improve the final stand and yield of bambara groundnut.

Since Botswana is a semi-arid country, it is subjected to erratic rainfall and also drought spells which greatly affect crop yield. This has called for a need to investigate and maximize the potential of more drought tolerant annual crops which are grown locally under rain-fed system. The crops include sorghum, millet and bambara groundnut. The purpose of this experiment was to investigate the potential of a simple pre-sowing hydration that might be useful to resource poor farmers.

\section{MATERIALS AND METHODS}

Three experiments were conducted on three bambara groundnut landraces; OM1, Diphiri cream (DC) and Gaborone cream (GC) in the greenhouse at Botswana College of Agriculture, Botswana, in 2011. Completely randomized designs (CRD) with 6 (including the control) pre-sowing hydration treatments replicated four times were used. OM1 is cream white and has a black butterfly around the 
hilum. DC is cream white and has a black dot around the hilum and GC is cream white all over (Linnemann and Azam Ali, 1993).

Seed germination; seeds were soaked at room temperature for five different pre-sowing hydration treatments; $(6,12,24,48,72 \mathrm{hrs})$ and the control by immersing them in distilled water in $500 \mathrm{ml}$ glass beakers. Seeds were air dried for 1 hour. The seeds were germinated between two layers of germination papers in petri dishes. Distilled water was added to moisten them when necessary. Four replicates were run for each treatment with 15 seeds. A seed was considered germinated when the radicle extension had read $10 \mathrm{~mm}$ (Garcia-Huidobro et al., 1982). Germination numbers were determined by counting germinated seeds. Germination was recorded for 15 days from placing the seeds in petri dishes and total germination percentage was calculated.

Emergence and early seedling growth; seeds were soaked at room temperature for five different presowing hydration treatments; $(6,12,24,48,72$ hrs) and the control by immersing them in distilled water in $500 \mathrm{ml}$ glass beakers. The seeds were then air dried for 1 hour. Seventy two (72) perforated plastic bags were filled with a composite growth medium (mixture of potting soil and loam soil). Then each pot was watered to field capacity and consequently moistened when required. Ten seeds were sown at 4 $\mathrm{cm}$ depth with four replicates pots per treatment. Twenty four (24) perforated plastic bags were used for seedling emergence and the remainders were for seedling growth. Seedling emergence observation was made daily for 15 days and the results recorded. A seedling was considered to have emerged when the epicotyl hook just appeared at the soil surface.

A seedling was randomly sampled from each replicate after 28 days including the 24 pots used for seedling emergence. An average of the three replicates from each set of the 24 pots was used to represent the replicate for each treatment. The seedlings were separated into shoots and roots. The roots samples were gently washed under tap water through a $2 \mathrm{~mm}$ mesh screen and soil free roots were collected. The shoots were further separated into stems and leaves. Stems, leaves and roots were dried separately in an oven at $80^{\circ} \mathrm{C}$ for 48 hours. The dry weights were recorded using a precision weighing balance (Ohaus, AR1530), max: $150 \mathrm{~g}$ and min: $0.001 \mathrm{~g}$.
Data analysis: The data collected was subjected to analysis of variance (ANOVA) using STATISTIX-8 program. Where F-test was observed and means comparison test carried out using Least Significant Difference (LSD) at $p \leq 0.05$ to separate treatment means.

\section{RESULTS AND DISCUSSIONS}

Germination: The final germination percentage, an important variable in understanding and predicting the effects of environment on germination differed within and across the landraces as influenced by the pre-sowing hydration treatments. Generally, it was high for bambara groundnut seeds soaked than unsoaked seeds (Table 1). Rashid et al. (2006) reported that priming enhanced germination, better establishment and increased yields in a wide range of crops in many diverse environments. Duration of presowing hydration strongly influenced the final germination of GC (Table 1). Increasing hydration from 12-72 hrs for GC significantly $(p \leq 0.01)$ increased the final germination percentage up to $87 \%$. However, in DC there was a significant decrease in final germination at 6 and $72 \mathrm{hrs}$ as compared to the control whereas, only a slight significant increase in the final germination percentage was recorded for OM1 (Table 1). Differences between the landraces may be associated with variation in mechanical resistance offered by testa or other germination inhibitors that slow down water uptake by seeds (Rolstor et al., 1978; Asgedom and Becker, 2001; Khan et al., 2008; Yari et al., 2011).

In the GC landrace, pre-sowing hydration softened the testa and allowed for the leakage of germination inhibitors which were present in the seed and this resulted in increased seed germination as observed by Habib et al. (1990). Chiu et al. (2002) also observed similar results of enhanced germination in sweet sorghum when primed. The optimum soaking time for all the landraces was 24 hrs. Hydrating these landraces for $24 \mathrm{hrs}$ improved the total germination. Soaking seeds for a predetermined period accelerates germination (Modi, 2005). Habib et al. (1990) indicated that soaking tea seeds for over 1-3 days resulted in higher germination percentage. 


\section{Emergence}

Maximum seedling emergence in all bambara landraces was achieved following $24 \mathrm{hrs}$ of hydration. There were significant differences $(p \leq 0.01)$ within and across the landraces as influenced by the hydration treatments (Table 1). GC had the highest seedling emergence when compared to DC and OM1 (Table 1). For all the three landraces, moisture content of seeds is critical for both germination and seedling emergence stages as reported by Hadas and Russo (1974). Parera and Cantliffe (1994); Harris (1996); Taylor et al. (1998) reported that pre-sowing is a common treatment that increase the rate and uniformity of emergence in many vegetables and field crops. The direct benefits of seed priming in all crops included faster emergence, better, more and uniform stands, less need for re-sowing, more vigorous plants, better drought tolerance, earlier flowering, earlier harvest and higher grain yield (Harris et al., 2001a). The probable reason for early emergence of the primed seed may be due to the pre-germinative metabolic activities making the seed ready for radicle protrusion and the primed seed germinated soon after planting as compared to untreated dry seed (Heydecker and Coolbear, 1977).

Table 1 Effect of soaking on the germination and seedling emergence of three bambara groundnut landraces.

\begin{tabular}{|c|c|c|c|c|c|c|c|c|}
\hline \multirow[t]{2}{*}{ Treatments } & \multicolumn{3}{|c|}{ Mean Germination (\%) } & \multirow[t]{2}{*}{ Sig. } & \multicolumn{3}{|c|}{ Mean Emergence (\%) } & \multirow[t]{2}{*}{ Sig. } \\
\hline & GC & DC & OM1 & & GC & DC & OM1 & \\
\hline 0 hrs & $67^{\mathrm{bA}}$ & $63^{\mathrm{aA}}$ & $37^{\mathrm{CB}}$ & & $73^{\mathrm{CA}}$ & $35^{\mathrm{bB}}$ & $42^{\mathrm{bcB}}$ & \\
\hline $6 \mathrm{hrs}$ & $73^{\mathrm{bA}}$ & $30^{\mathrm{CB}}$ & $40^{\mathrm{DCB}}$ & & $61^{\mathrm{dA}}$ & $27^{\mathrm{CB}}$ & $33^{\mathrm{dB}}$ & \\
\hline $12 \mathrm{hrs}$ & $87^{\mathrm{aA}}$ & $47^{\mathrm{DB}}$ & $43^{\mathrm{DCB}}$ & & $84^{\mathrm{DA}}$ & $38^{\mathrm{bC}}$ & $46^{\mathrm{DB}}$ & \\
\hline 24 hrs & $87^{\mathrm{aA}}$ & $63^{\mathrm{aB}}$ & $57^{\mathrm{aB}}$ & & $100^{\mathrm{aA}}$ & $63^{\mathrm{aB}}$ & $67^{\mathrm{aB}}$ & \\
\hline 48 hrs & $87^{\mathrm{a} A}$ & $57^{\mathrm{aB}}$ & $47^{\mathrm{DB}}$ & & $81^{\mathrm{bcA}}$ & $27^{\mathrm{CC}}$ & $38^{\mathrm{CdB}}$ & \\
\hline 72 hrs & $87^{\mathrm{a} A}$ & $23^{\mathrm{CB}}$ & $23^{\mathrm{dB}}$ & & $61^{\mathrm{dA}}$ & $31^{\mathrm{DCB}}$ & $31^{\mathrm{dB}}$ & \\
\hline \multicolumn{9}{|l|}{ Significance } \\
\hline LSD 0.05 & 10.36 & 8.14 & 9.16 & & 8.65 & 7.02 & 7.26 & \\
\hline CV (\%) & 8.58 & 11.61 & 14.97 & & 7.60 & 12.83 & 11.41 & \\
\hline
\end{tabular}

** highly significant at $p \leq 0.01$. Means separated by Least Significance Difference (LSD) Test at $p \leq 0.05$, means within columns followed by the same letters (lowercase) are not significantly different and means within rows followed by the same letters (uppercase) are not significantly different.

Leaf, stem and root dry matter: Soaking had no significant ( $p>0.05)$ effect statistically on GC and DC leaf dry matter production as compared to the control (Table 2). However, $12 \mathrm{hrs}$ and $24 \mathrm{hrs}$ had the highest leaf dry matter for GC and DC respectively. Mixed results were observed for OM1 with the control and 24 hrs significantly ( $p \leq 0.05)$ increasing the leaf dry matter whereas, $6 \mathrm{hrs}$ and $48 \mathrm{hrs}$ significantly $(p \leq 0.05)$ reduced the leaf dry matter (Table 2). Moreover, across the three landraces, GC and DC significantly increased the leaf dry matter at 6, 12, 48 and $72 \mathrm{hrs}$ and all the landraces were non-significant at 0 and $24 \mathrm{hrs}$ (Table 2). The differences in total leaf dry matter within and across the landraces could be due to germination and emergence time. The measured growth parameters indicate that the increased leaf dry matter was not simply due to earlier germination and emergence but the hydration of seeds actually increased the growth rates (Table 2). Farahini and Maroufi (2011) reported that hydropriming increased the germination percentage, seedling vigor and seedling dry matter of basil crop.
In another experiment, Maroufi and Farahini (2011) found similar results in garden pea.

Pre-sowing hydration had no significant $(p>0.05)$ effect statistically on GC and OM1 stem dry matter production as compared to the control (Table 2). GC had the highest stem dry matter at $6 \mathrm{hrs}$ to $24 \mathrm{hrs}$ whereas, the control had the highest dry matter for OM1 (Table 2). Soaking for 24 hrs significantly increased the stem dry matter of DC as compared to the control (Table 2). Across the three landraces, GC and DC significantly ( $p \leq 0.05)$ increased the stem dry matter at 6, 12 and $24 \mathrm{hrs}$ (Table 2). Yari et al. (2011) found that priming on different wheat varieties produced different overall dry matter. The differences could be because of the different genetic traits of the three bamabara landraces. Yari et al. (2011) also revealed variation in the mean value for pods, grain weight and biological yield of priming treatments. Although the mean values were variable, the parameters recorded high values for primed seed when compared with unprimed seed. Heckel (1964); Scotte et al. (1973); Harris et al. (2001c) reported that 
early emergence from primed seed might have enhanced yield by increasing the amount of light intercepted by the canopy. Farooq et al. (2006) is in agreement that osmo-hardening improved germination, emergence and yield of rice crop.

Pre-sowing hydration had significant $(p \leq 0.01)$ effect within the three bambara landraces (Table 2). Root dry matter was significantly increased at $6 \mathrm{hrs}$ for GC, whereas, 6 hrs and 72 hrs significantly increased root dry matter for DC. Hydration significantly increased the root dry matter at 72 hrs for OM1 (Table 2). Pre- sowing hydration for $72 \mathrm{hrs}$ had no effect across the three landraces whereas; the other treatments had a significant $(p \leq 0.01)$ effect on root dry matter (Table $2)$. The result are similar to other findings where different landraces and hours of hydration showed different responses in other parameters in maize for number of cobs per plant, number of grains per cob and cob weight per plant (Mushraf et al., 2013). Similar results were reported by Hussain et al. (2008) on variation in 1000 achenes weight, number of achenes per head and achene yield of sunflower.

Table 2 Effect of soaking on leaf, stem and root dry matter of three bambara groundnut landraces.

\begin{tabular}{|c|c|c|c|c|c|c|c|c|c|c|c|c|}
\hline Treatments & \multicolumn{3}{|c|}{ Leaves dry matter (g) } & Sig. & \multicolumn{3}{|c|}{ Stem dry matter (g) } & Sig & \multicolumn{3}{|c|}{ Roots dry matter (g) } & Sig \\
\hline & $\mathrm{GC}$ & $D C$ & OM1 & & $\mathrm{GC}$ & $\mathrm{DC}$ & OM1 & & $\mathrm{GC}$ & $\mathrm{DC}$ & OM1 & \\
\hline 0 hrs & 1.40 & 1.40 & $1.00^{\mathrm{a}}$ & $\mathrm{ns}$ & 0.04 & $0.04^{\mathrm{b}}$ & 0.04 & ns & $0.17^{\mathrm{dB}}$ & $0.24^{\mathrm{DA}}$ & $0.26^{\mathrm{aA}}$ & \\
\hline $6 \mathrm{hrs}$ & $1.70^{A}$ & $1.45^{\mathrm{A}}$ & $0.60^{\mathrm{bC}}$ & & $0.05^{A}$ & $0.05^{\mathrm{DAB}}$ & $0.03^{B}$ & & $0.34^{\mathrm{aA}}$ & $0.33^{\mathrm{aA}}$ & $0.23^{\mathrm{DB}}$ & \\
\hline $12 \mathrm{hrs}$ & $1.71^{\mathrm{A}}$ & $1.25^{\mathrm{B}}$ & $0.80^{\mathrm{abc}}$ & & $0.05^{A}$ & $0.04^{\text {DAB }}$ & $0.03^{\mathrm{B}}$ & & $0.27^{\mathrm{DA}}$ & $0.19^{\mathrm{CB}}$ & $0.19^{\mathrm{CB}}$ & \\
\hline 24 hrs & 1.70 & 1.50 & $1.00^{\mathrm{a}}$ & ns & $0.05^{\mathrm{AB}}$ & $0.07^{\mathrm{aA}}$ & $0.04^{\mathrm{B}}$ & & $0.22^{\mathrm{CA}}$ & $0.17^{\mathrm{CB}}$ & $0.18^{\mathrm{CB}}$ & \\
\hline $48 \mathrm{hrs}$ & $1.60^{\mathrm{A}}$ & $2.00^{A}$ & $0.65^{\mathrm{bB}}$ & & 0.04 & $0.04^{\mathrm{b}}$ & 0.03 & ns & $0.23^{\mathrm{CA}}$ & $0.24^{\mathrm{bA}}$ & $0.14^{\mathrm{dB}}$ & \\
\hline 72 hrs & $1.45^{\mathrm{A}}$ & $1.15^{\mathrm{AB}}$ & $0.85^{\mathrm{abB}}$ & & 0.04 & $0.04^{D}$ & 0.03 & ns & $0.27^{0}$ & $0.30^{\mathrm{a}}$ & $0.29^{a}$ & ns \\
\hline Significance & ns & ns & & & ns & & ns & & & & & \\
\hline LSD 0.05 & 0.63 & 0.69 & 0.30 & & 0.01 & 0.01 & 0.01 & & 0.04 & 0.04 & 0.03 & \\
\hline CV (\%) & 26.61 & 31.77 & 24.57 & & 18.14 & 21.43 & 24.44 & & 9.43 & 10.88 & 9.79 & \\
\hline
\end{tabular}

* significant at $p \leq 0.05,{ }^{* *}$ highly significant at $p \leq 0.01,{ }^{n s}$ non-significant at $p>0.05$. Means separated by Least Significance Difference (LSD) Test at $p \leq 0.05$, means within columns followed by the same letters (lowercase) are not significantly different and means within rows followed by the same letters (uppercase) are not significantly differen

\section{CONCLUSION}

Hydrating seeds for 24 hours improved germination, seedling emergence, leaf and stem dry matter accumulation of bambara groundnut landraces. Results of this study may have significant agronomic implication for the establishment of the crop. Bambara groundnut may benefit from pre-sowing hydration resulting in better germination and seedling emergence. The farmers may benefit from a good start of the crop using this relatively simple and inexpensive technology especially in semi-arid countries like Botswana.

\section{ACKNOWLEDGEMENTS}

The authors greatly acknowledge the support that the Ministry of Education gave to Kgomotso Mogamisi. We owe our gratitude to Botswana College of Agriculture for providing resources including laboratory facilities.

\section{REFERENCES}

Asgedom, $\mathrm{H}$ and Becker, $\mathrm{M}$ (2001). Effect of seed priming with nutrient solutions germination, seedling growth and weed competitiveness of cereals in Eritrea. In: Proc. Deutscher Tropetag 2001, University of Bonn and ATSAF, Margraf publishers press, Weickershein. p.282.

Berchie, J. N., Adu-Dapaah, J., Sarkodie, E., Asare, A., Agyemang, S., Addy, S and Donkoh, J (2011). Effect of seed priming on seedling emergence and establishment of four bambara groundnut (Vigna subterranean L. Verdic) landraces, Journal of Agronomy, 9: 180-183.

Chiu, K. Y., Chen, C. L and Sing, J. M (2002). Effect of priming temperature on storability of sh-2 sweet corn seed. Crop Science, 42: 1996-2003.

Farahini, H. A and Maroufi, K (2011). Effects of hydropriming on seedling vigour in basil (Ocimum basilium L.) under salinity conditions. Advances in Environmental Biology, 5: 828-833. 
Farooq, M., Basra, S. M. A and Rehman Hafeez, U (2006). Seed priming enhances emergence, yield and quality of direct-seeded rice crop management and physiology. p.42-44.

Garcia-Huidobro, J., Monteith, J. L and Squire, G. R (1982). Time, temperature and germination of pearl millet (Pennisetum typhoides). Alternating temperature. Journal of Experimental Botany, 33: 297302.

Habib, G. S. M and Khalid, A. U. H (1990). Observation on the germination of tea seed variety Q1-men as influenced by soaking, shell removal and shell cracking. Pakistan Journal of Science and Research, 33: $5-6$.

Hadas, A and Russo, D (1974). Water uptake by seeds as affected by water stress, capillary conductivity and seed-soil water contact. Experimental study. Agronomy Journal, 66: 643-647.

Harris, D (1996). The effects of manure, genotype, seed priming, depth and date of sowing on the emergence and early growth of Sorghum bicolor (L) Moench in semi-arid Botswana. Soil and Tillage Research, 40: 73-78.

Harris, D., Kumar Rao, J. V. D. K and Kumar, J (2001a). On-farm seed priming. Agricultural Research and Extension Network newsletter, 44:3.

Harris, D., Raghuwanshi, J. S., Gangwar, S. C., Singh, K. D., Joshi, A., Rashid, A and Hollington, P. A (2001c). Paricipatory evaluation by farmers of on-farm seed priming in wheat in Nepal, India and Pakistan. Experimental Agriculture, 37: 403-415.

Heckel, P. A (1964). Physiology of plants under drought. Annual Review of Plant Physiology. 15: 363-386.

Heydecker, W and Coolbear, P (1977). Seed treatments for improvements performance survey and attempted prognosis. Seed Science and Technology, 5: 353-425.

Hussain, M., Farooq, M., Shahzad M. A. Basra and Ahmad, $N$ (2008). Influence of seed priming techniques of seedling establishment, yield and quality of hybrid of sunflower. International Journal of Agriculture and Biology, 1: 14-18.

Khan, A., Khalil, S. K., Khan, A. Z., Marwat, K. B and Afzal, $A$ (2008). The role of seed priming in semi-arid area for mungbean phenology and yield. Pakistan Journal of Botany, 40: 2471-2480.

Linnemann, A. R (1990). Cultivation of bambara groundnut (Vigna subterranean) in Western Province, Zambia. Report of field study. Tropical Crops Communication.

Linnemann, A. R and Azam-Ali, S. N (1993). Bambara groundnut (Vigna subterranean) In: Williams, J. T. ed. Underutilized compared with Diphiri cream and Diphiri groups, series II. Pulses and Vegetables. London: Chapman and Hall. p.13-58.

Maroufi, $\mathrm{K}$ and Farahini, H. A (2011). Effects of hydropriming on germination percentage in garden pea. Advances in Enviromental Biology, 5: 2220-2223.

Modi, A. T (2005). Assessment of pepper seed performance using desiccation sensitivity. Seed Science Technology, 33: 19-30.

Musharaf, K., Asim, M., Shah, F. M., Ullah, S., Saadullah, K and Subhan, M (2013). Response of maize yield and yield components to hydropriming durations in rainfed Region of Bannu. eJournal of Biological Sciences, 6: 12-16.

Parera, C. A and Cancliffe, D. J (1994). Pre-sowing seed priming. Horticultural Sciences, 16: 109-141.

Rashid, A., Hollington., P. A., Harris, D and Khan, P (2006). On-farm seed priming for barley on normal, saline and sodic-saline soils in North West frontier Province of Pakistan using on-farm seed priming. Europe Journal of Agronomy, 24: 276-281.

Rolston, M. P (1978). Water impermeable seed dormancy. The Botanical Review, 44: 365-396.

Scotte, R. K., English, S. D., Wood S and Nsworth, M. H. U (1973). The yield of in relation to weather and length of growing season. Journal of Agriculture Science, 81: 339-347.

Taylor, A. G., Allen, P. S., Bennet, M.A., Bradford, K. J., Burris, J. S. and Misra, M. K (1998). Seed Enhancement. Seed Science Research, 8: 245-256.

Yari, L., Abbasian, A., Oskouei, B and Sadeghi, H (2011). Effect of seed priming on dry matter, seed size and morphological characters in wheat cultivar. Agriculture and Biology Journal of North America, 2: 232-238. 